\title{
A INDÚSTRIA FOI EMBORA, E AGORA? \\ Discussões e experiências sobre as áreas industriais ociosas no Grande ABC Paulista, 1989-2019
}

\section{THE INDUSTRY WAS GONE AWAY, WHAT NOW? Discussions and experiences on industrial void areas in the Great $A B C$ Paulista, 1989-2019}

\author{
A. Gisele Yamauchi \& B. Andréa de Oliveira Tourinho \\ PGAUR-USJT, Universidade São Judas Tadeu, Brasil. \\ giseleyamauchi@yahoo.com.br \\ prof.atourinho@usjt.br
}

\begin{abstract}
RESUMO
Este trabalho objetiva apresentar as discussões e experiências sobre as áreas industriais ociosas decorrentes do processo de reestruturação industrial, nos últimos trinta anos, na Região do Grande $A B C$ Paulista, situada na área metropolitana de São Paulo, e composta por sete municípios. Durante a década de 1990 , atores locais, regionais e profissionais internacionais buscaram discutir ações e projetos para essas áreas industriais sem atividade. Discussões que se expressaram na criação de novos órgãos de gestão, que buscavam promover o crescimento sustentável da Região. Foi realizada pesquisa que apontou uma reconfiguração das características dessas áreas entre o período de 1989 e 2019, verificando-se o desconhecimento da nova situação e a falta de discussão mais recente sobre a problemática. No século XXI, a situação é mais grave, pois o problema continua atual, mas há um enfraquecimento da discussão nas esferas municipais e regional, sendo um dos maiores desafios a ser vencido pela Região.
\end{abstract}

Palavras-chave: Reestruturação produtiva, áreas industriais ociosas, Região do Grande $A B C$, gestão urbana.

Linha de Investigação: 1 . Cidade e projeto.

Tópico: Planejamento, políticas e governança.

\section{ABSTRACT}

This work aims to present the discussions and experiences about the industrial void areas resulting from the industrial restructuring process, in the last thirty years, in the Greater ABC Region composed of seven municipalities and located in São Paulo Metropolitan Area. During the 1990s, national and international professionals sought to discuss actions and projects for these industrial void areas. Discussions were expressed in the creation of new management bodies, which sought to promote sustainable growth in the Region. The research pointed out a reconfiguration of the characteristics of these areas between 1989 and 2019. There is a lack of knowledge and an absence of recent discussions about the new situation. In the 21 st 


\section{SÃO PAULO15 17 LISBOA $25 \sim 26$ JUN 2020

century, the situation is more serious, as the problem remains current, but there is a weakening of the discussion at the municipal and regional levels, being one of the greatest challenges to be overcome by the Region.

Keywords: Productive restructuring, industrial voids areas, Greater ABC Region, urban management. Research line: 1. City and project.

Topic: Planning, Policies and Governance.

\section{Introdução}

Este trabalho tem como objetivo apresentar as discussões e experiências sobre as áreas industriais ociosas decorrentes do processo de reestruturação industrial na Região do Grande ABC Paulista, situada na Região Metropolitana de São Paulo. Esta importante região industrial é composta pelos municípios de Santo André, São Bernardo do Campo, São Caetano do Sul, Diadema, Mauá, Ribeirão Pires e Rio Grande da Serra. O referido processo levou à saída de muitas empresas na Região do Grande ABC nos últimos trinta anos. Contudo, a problemática adquiriu novas nuances e intensificou-se, como será mostrado, neste trabalho. Ainda assim, a dimensão do problema é desconhecida pelos atores sociais da Região e as discussões diminuíram. Durante a década de 1990, os atores locais, regionais e profissionais internacionais buscaram discutir ações e projetos para essas áreas industriais sem atividade: desde novos empreendimentos, manutenção das indústrias na região e, ainda, constituição de novas centralidades econômicas na escala municipal e regional. Essas discussões se expressaram, também, na criação de novos órgãos de gestão: a Câmara Regional, o Consórcio Intermunicipal, a Agência de Desenvolvimento Econômico do Grande ABC, que buscavam promover o crescimento econômico, social e sustentável da Região. No século XXI, a situação é mais grave, pois há um enfraquecimento da discussão na esfera regional e a diminuição do protagonismo da Agência de Desenvolvimento Econômico do ABC.

A hipótese de trabalho é a de que velhas e novas questões estão presentes na Região, reproduzindo as ideias anteriores, mesmo com os novos nuances da questão. $O$ trabalho parte do pressuposto de que os conflitos de interesse, a não inclusão da sociedade civil nos debates e o ciclo eleitoral exerceram um grande impacto na discussão sobre a problemática, prejudicando os estudos e a implantação de novas soluções para essas áreas. Pretende-se resgatar os marcos do debate sobre o assunto, mostrando o estado da arte desse debate sobre as áreas industriais sem atividade que ainda fazem parte da paisagem urbana dos sete municípios, verificando-se que, ainda nas duas primeiras décadas do século XXI, os projetos de intervenção urbana continuam seguindo a lógica do consumo e da especulação imobiliária da década de 1990.

Como procedimento metodológico, utiliza-se a pesquisa bibliográfica, de caráter histórico, bem como os dados da pesquisa em andamento, desde 2018, sobre as áreas industriais ociosas na Região do Grande $A B C$, que contou com levantamentos de campo e entrevistas com os técnicos e gestores dos sete municípios. Entre as mais de 300 áreas antes industriais, e agora disponíveis para venda ou locação no mercado, não estão apenas grandes áreas a partir de $30.000 \mathrm{~m}^{2}$, como no início, mas também pequenas (entre $4.000 \mathrm{~m}^{2}-6.999 \mathrm{~m}^{2}$ ), médias (entre $7.000 \mathrm{~m}^{2}-9.999 \mathrm{~m}^{2}$ ) e novas grandes áreas (a partir de 10.000 $\mathrm{m}^{2}$ ), bem como antigas áreas que permanecem sem solução desde a década de 1990. Considerando essas diferentes dimensões das áreas industriais ociosas na Região do Grande ABC, este trabalho busca refletir sobre as seguintes questões: como andam os debates sobre essa problemática na atualidade? Quais são as experiências (projeto, ações) realizadas nessas áreas? 


\section{SÃO PAULO15 $17 \cdot$ LISBOA $25 \sim 26$ JUN 2020

\section{Os marcos do debate sobre o problema das áreas industriais ociosas}

Desde o seu surgimento, as cidades industriais passaram por várias transformações, decorrentes das mudanças nos modos de produção. Nas últimas décadas, a partir de uma série de transformações políticas e econômicas, o estado de bem-estar social (Welfare State), o sistema de produção fordista e o modelo hegemônico unipolar norte-americano, que foram as bases de reconstrução do Pós-Segunda Guerra Mundial, passaram a ser colocados em xeque a partir dos anos 1970 (Hobsbawm, 2015).

Muitos autores apontam este momento como a passagem de uma sociedade industrial para uma era da informação e do conhecimento, iniciada pela terceira revolução industrial devida à globalização, aos avanços científicos e tecnológicos nas telecomunicações, informática e transportes (Hobsbawm, 2015). No contexto urbano, para as cidades industriais, que já acumulavam problemas não resolvidos da intensa urbanização de décadas anteriores, a transição do modelo industrial para a sociedade do conhecimento, traduziu-se na intensificação de processos excludentes de produção do espaço (Archer, 2010).

Essas mudanças implicaram no fortalecimento das ideias neoliberais, levando a uma série de alterações nos modelos de gestão pública e privada. Na gestão pública, o mote passa a ser o de diminuição da participação do Estado em todas as esferas da gestão pública. Na gestão privada, houve mudanças na estratégia das empresas, o que levou a uma reestruturação produtiva, seja no desenho de novos produtos, na estrutura do processo produtivo, nos modelos de relações de trabalho e, mesmo, na ocupação territorial fabril. A transferência de linhas de produção para países que ofereciam menores custos de produção (principalmente o de mão-de-obra) provocou a saída de empresas das cidades, e, como resultado, o surgimento das áreas industriais ociosas (em inglês, Industrial Void Areas; em francês, Friches Industrielles) em várias cidades, como em Detroit, Bordeaux, cidades do Vale do Ruhr na Alemanha, entre outras (Conceição, 2006; Archer, 2010; Hobsbawm, 2015).

No Brasil, o fenômeno das áreas industriais ociosas surgiu na década de 1990 com a reestruturação industrial, levando à transferência de linhas de produção de suas localidades originais para outros estados ou países e o fechamento de fábricas. Desde então, a Região do Grande ABC sofre com essa problemática, pendente de soluções sustentáveis, cujo sucesso depende de ações concertadas entre os vários agentes sociais da região.

O processo de industrialização da Região do Grande ABC ocorreu a partir de 1890, com o surgimento de empresas do setor de vestuário e alimentos, entre outros, em galpões ao longo da linha férrea. No período de 1955 a 1989, a Região concentrou investimentos, principalmente de capital estrangeiro do setor automotivo e químico, ao longo de rodovias, transformando-se no maior cluster industrial da América Latina.

A partir de 1990, ocorreram mudanças, marcadas pela reestruturação industrial, a globalização, a financeirização da economia, o neoliberalismo, bem como dificuldades econômicas internas que deflagraram o processo de saída das indústrias do Grande $A B C$, levando ao surgimento das áreas industriais ociosas. Moro Júnior (2007) e Teixeira (2010) afirmam que as respostas que têm sido dadas ao problema, em geral, são pontuais e atendem à lógica da especulação imobiliária e do consumo, havendo a transformação de grandes galpões fabris em shoppings, hipermercados e até mesmo igrejas. Essa lógica prevaleceu inclusive nos projetos públicos, que se afastaram de propósitos mais amplos considerados inicialmente, devido à crise econômica que assolava o país, bem como à instalação do modelo político e econômico neoliberal no país nas últimas décadas. A Fig. 1 mostra a expansão da industrialização de a desconcentração industrial na Região do Grande ABC Paulista a partir do ano de 1890 até 1997. 


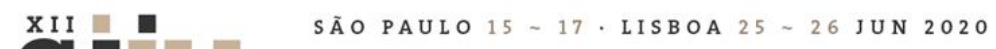 \\ SIIUl $=-m$}
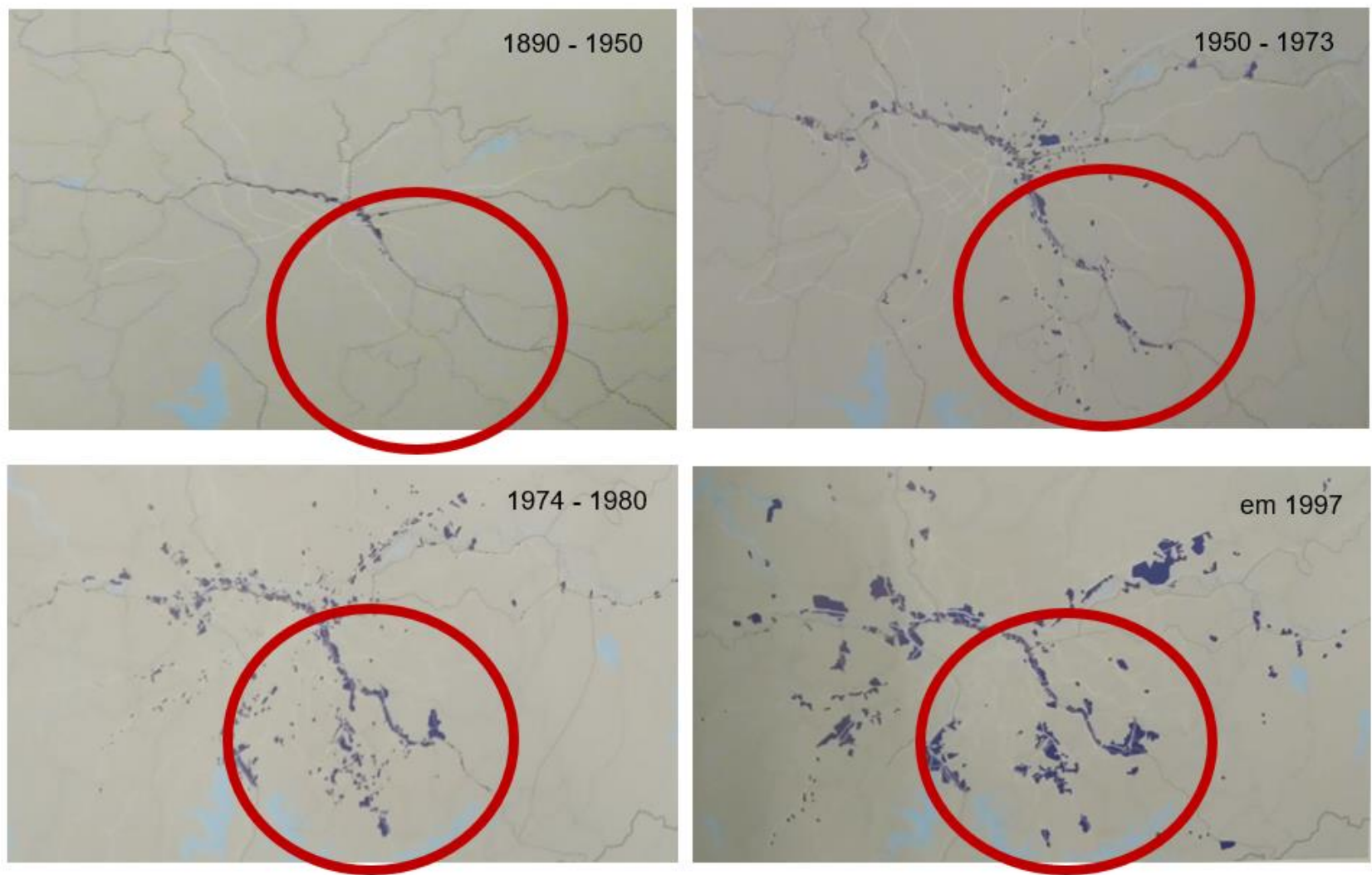

Fig. 1. Expansão e desconcentração industrial na Região do Grande ABC entre 1890 e 1997.

Fonte: (Meyer, Grostein, Biderman, 2004: p.166-167).

Embora a Região tenha passado por um processo de revitalização econômica durante o período compreendido entre 2003 e 2014, a problemática das áreas industriais ociosas permaneceu como parte da paisagem urbana e social, e se constitui, ainda hoje, como um grande desafio a ser enfrentado pelos atores locais na busca de soluções para a Região.

\section{As discussões e experiências nas áreas industriais ociosas na Região do Grande ABC entre 1990 e 2006}

Diante do problema comum da saída das empresas, os prefeitos de todos os municípios da Região do Grande ABC, sob a iniciativa do prefeito andreense Celso Daniel, discutiram as formas de como convencer as empresas a permanecerem na Região. A década de 1990 foi um dos períodos mais draconianos para a Região, conforme pode ser visto na Tab. 1: 


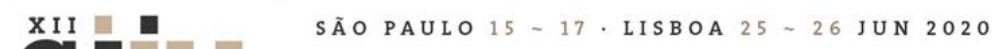

Tamanho do estabelecimento por no de empregados

Total de estabelecimentos industriais no Grande ABC, por tamanho, no período entre 1989 - 1999

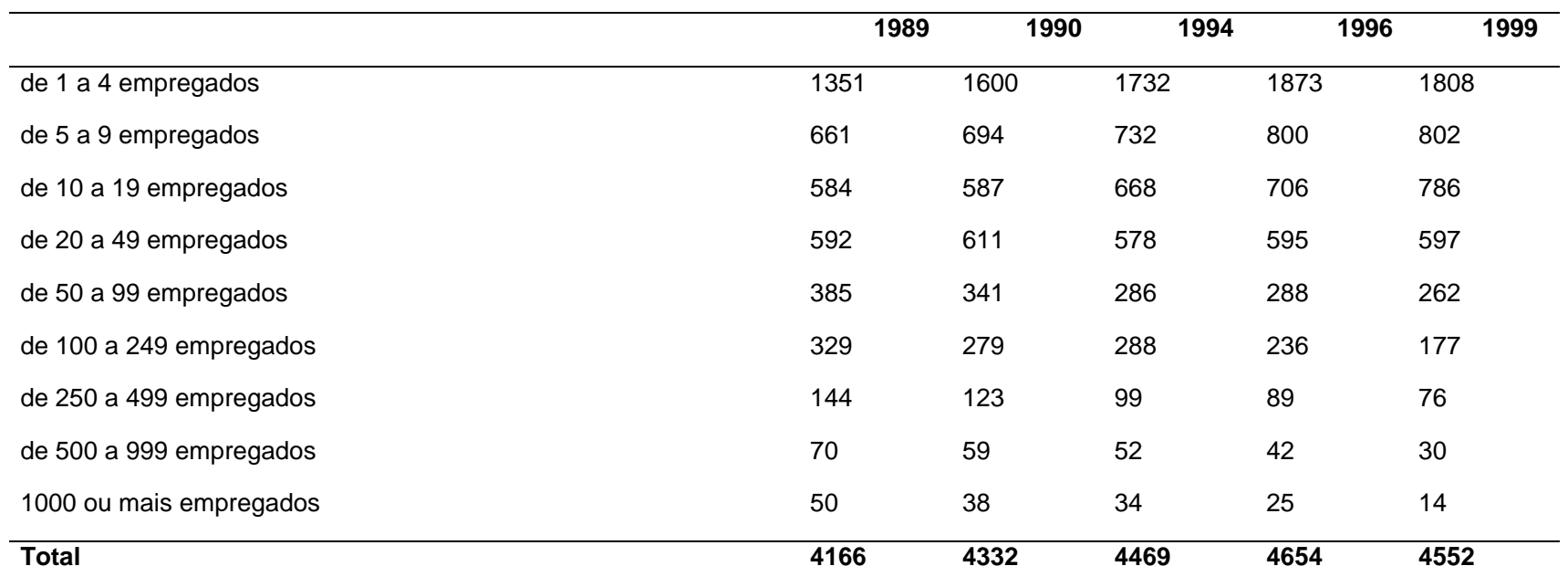

Tab. 1. Total de Estabelecimentos Industriais no Grande ABC, por tamanho, no período entre 1989 - 1999. Fonte: Elaborado própria, a partir de informações da RAIS, Ministério da Economia, 2019.

Os grandes galpões degradados e abandonados (a maioria com área a partir de $30.000 \mathrm{~m}^{2}$ ) passaram a fazer parte da paisagem urbana das cidades da Região. Essas áreas industriais ociosas passaram a ser objeto de debate, em que foram discutidas várias soluções: reutilização do espaço ou galpão por outra indústria, obras de intervenção urbana no local com outro tipo de uso (como, por exemplo, comércio, serviços e habitação) ou a criação de áreas culturais, de lazer e de equipamentos turísticos (Klink, 2001; Conceição, 2006).

Em maio de 1997 foi realizado um Seminário Internacional, em que os atores sociais da região e profissionais renomados do Brasil e do exterior discutiram novas soluções para essas áreas industriais ociosas (Tourinho \& Yamauchi, 2019). No encontro, foram citados vários exemplos, como a cidade de Detroit, Bordeaux, Roterdã, Leipizig, Região da Galícia na Espanha, Região do Norte da Inglaterra. A partir dessas ideias que foram discutidas intensamente na década de 1990, foi concebido o Projeto Eixo Tamanduatehy, que procurava atrelar projetos considerando os diferentes interesses, incluindo projetos de cunho social. Entretanto, Moro Júnior (2007) afirma que o sucesso dos projetos executados na cidade de Barcelona, e sobretudo a visita do arquiteto catalão Jordi Borja ao Brasil em 1998, acabou influenciando os projetos de intervenção urbana. O país passava por problemas econômicos, sobretudo, queda da arrecadação fiscal. Como as políticas neoliberais começaram a ser implantadas no âmbito da gestão pública, as ações planejadas para o Projeto Eixo Tamanduatehy tiveram que ser repensadas. Segundo Teixeira (2010), os projetos passaram a ter maior visibilidade para 0 mercado de consumo e imobiliário. $\mathrm{Na}$ Tab. 2 constata-se, de fato, que a maioria dos projetos está voltada para a lógica de mercado, sendo poucos voltados para uma ação social ampla. 


\section{SÃO PAULO15 17 LISBOA 25 26 JUN 2020 \\ Seminário Internacional de Seminario Internacional de Investigação em Urbanismo Investigación en Urbanismo}

\begin{tabular}{|c|c|c|c|c|c|c|}
\hline Projeto & Descrição & Local & Início & Fim & $\begin{array}{l}\text { Terreno } \\
\left(\mathrm{m}^{2}\right)\end{array}$ & $\begin{array}{l}\text { Edificação } \\
\left(\mathrm{m}^{2}\right)\end{array}$ \\
\hline $\begin{array}{l}\text { Conjunto Residencial } \\
\text { lbatiba - } 900 \mathrm{UH}\end{array}$ & $\begin{array}{l}\text { Conjunto residencial } \\
\text { de renda média }\end{array}$ & Av. Utinga & 2000 & 2004 & 50.400 & 55.000 \\
\hline Campus UniABC & Execução de viário & Av. Industrial & 1997 & 2000 & 32.300 & 77.000 \\
\hline $\begin{array}{l}\text { Praça Samuel de } \\
\text { Castro Neves }\end{array}$ & $\begin{array}{l}\text { Reurbanização de } \\
\text { praça }\end{array}$ & Av. dos Estados & 2001 & 2001 & 11.900 & - \\
\hline TERSA & $\begin{array}{ll}\text { Implantação } & \text { de } \\
\text { rodoviária } & \\
\end{array}$ & Av. Industrial & 1997 & 2000 & 25.200 & 20.000 \\
\hline Strong/FGV & $\begin{array}{l}\text { Escola de Pós- } \\
\text { Graduação }\end{array}$ & Av. Industrial & 2000 & 2001 & 3.000 & 2.500 \\
\hline Vigorito & $\begin{array}{l}\text { Concessionária de } \\
\text { veículos }\end{array}$ & Av. Industrial & 2001 & 2003 & 21.600 & 4.600 \\
\hline Casa de show Status & $\begin{array}{l}\text { Equipamento artístico } \\
\text { cultural }\end{array}$ & Av. dos Estados & 2004 & 2004 & 8.700 & 3.200 \\
\hline Hotel Ibis e Mercure & Conjunto hoteleiro & Av. Industrial & 1998 & 2003 & 5.400 & 16.500 \\
\hline $\begin{array}{l}\text { Ampliação do Parque } \\
\text { Celso Daniel }\end{array}$ & $\begin{array}{l}\text { Incremento de área } \\
\text { verde }\end{array}$ & Av. Industrial & 1999 & 2000 & 3.600 & - \\
\hline Shopping ABC Plaza & $\begin{array}{ll}\text { Novo } & \text { viário } \\
\text { implantado } & \\
\end{array}$ & Av. Industrial & 1996 & 1997 & 96.000 & 54.200 \\
\hline $\begin{array}{l}\text { Supermercado } \\
\text { Carrefour }\end{array}$ & $\begin{array}{l}\text { Execução de área } \\
\text { verde e de lazer }\end{array}$ & Av. dos Estados & 2001 & 2003 & 43.000 & 15.000 \\
\hline $\begin{array}{l}\text { Supermercado Pão de } \\
\text { Açúcar II }\end{array}$ & $\begin{array}{l}\text { Área verde sob } 0 \\
\text { viaduto } 18 \text { do Forte }\end{array}$ & Av. dos Estados & 2003 & 2003 & 43.350 & - \\
\hline Rhodia Têxtil & $\begin{array}{l}\text { Implantação de } \\
\text { equipamento industrial }\end{array}$ & Av. dos Estados & 2000 & 2002 & - & - \\
\hline SEST / SENAT & $\begin{array}{l}\text { Complexo voltado } \\
\text { para os trabalhadores } \\
\text { dos transportes }\end{array}$ & $\begin{array}{l}\text { Rua Vereador José } \\
\text { Nanci }\end{array}$ & 1998 & 2002 & 58.000 & 4.600 \\
\hline Cond. Ind. Franchini & Execução de viário & Rua Ângelo Franchini & 1999 & 2004 & 15.186 & 8.855 \\
\hline CODEMA & Concessionária & Av. dos Estados & 2004 & 2005 & 5.200 & 1.700 \\
\hline Makro & Loja atacadista & Av. dos Estados & 2003 & 2005 & 20.000 & 8.000 \\
\hline Auto Shopping Global & Execução de viário & Av. dos Estados & 1999 & 2000 & 70.000 & 50.300 \\
\hline Cidade Pirelli - Fase II & $\begin{array}{l}\text { Sede tecnológica da } \\
\text { TIM }\end{array}$ & $\begin{array}{ll}\text { R. Alexandre de } \\
\text { Gusmão }\end{array}$ & 2005 & 2005 & 59.000 & 42.000 \\
\hline Cidade Pirelli - Fase I & $\begin{array}{lcr}\text { Praça, escola } & \text { e } \\
\text { duplicação da } & \text { Av. } \\
\text { Giovanni } & \text { B. Pirelli }\end{array}$ & Av. Giovanni B. Pirelli & 1998 & 2000 & 26.629 & 1.375 \\
\hline $\begin{array}{ll}\text { Urbanização } & \text { da } \\
\text { Favela Capuava } & \\
\end{array}$ & $\begin{array}{l}\text { Urbanização da favela } \\
1.400 \text { famílias }\end{array}$ & Av. dos Estados & 1998 & 2006 & 100.000 & - \\
\hline \multirow[t]{3}{*}{ Resultados } & Total & & & & 703.465 & 364.830 \\
\hline & \multicolumn{2}{|c|}{ Área do Projeto Eixo Tamanduatehy } & \multicolumn{2}{|c|}{$12.130 .827,25 \mathrm{~m}^{2}$} & $5.80 \%$ & \\
\hline & \multicolumn{2}{|c|}{ Áreas subutilizadas e livres no Eixo } & \multicolumn{2}{|c|}{$3.835 .029,54 \mathrm{~m}^{2}$} & $18,34 \%$ & \\
\hline
\end{tabular}

Tab. 2. Empreendimentos e Intervenções Urbanas na Área do Eixo Tamanduatehy 1997-2006. Fonte: (Sakata, 2009).

Como se pode observar, a maioria das áreas industriais ociosas são superiores a $30.000 \mathrm{~m}^{2}$ - totalizando nove grandes áreas. Esses dados levam aos seguintes questionamentos, que serão discutidos neste 


\section{SÃO PAULO15 17 LISBOA $25 \sim 26$ JUN 2020

trabalho: o número de grandes galpões industriais ociosos (a partir de $30.000 \mathrm{~m}^{2}$ ) continua a fazer parte do cenário urbano ou o problema mudou? Considerando os projetos executados entre o período de 1997 e 2006, será que a lógica dos projetos segue sendo aquela voltada ao mercado de consumo e imobiliário na Região do Grande ABC?

\section{As áreas industriais ociosas na Região do Grande $A B C$ a partir de 2006}

O protagonismo exercido pelos atores sociais da Região do Grande ABC foi muito importante durante a década de 1990, pois muitas das áreas industriais ociosas no âmbito do Eixo Tamanduatehy passaram por intervenção urbana. Independente da crítica que possa ser feita a essas intervenções, é certo que essas ações contribuíram para o deslocamento de uma centralidade econômica da indústria de transformação para o setor de serviços na cidade de Santo André. Essas ações, sobretudo aquelas centradas no consumo e no mercado imobiliário, nas áreas industriais ociosas do Projeto Eixo Tamanduatehy, influenciaram os demais projetos realizados nas cidades da Região, como pode ser observado na Tab. 3:

\begin{tabular}{|c|c|c|c|}
\hline Cidade & Áreas industriais & Projetos de intervenção urbana & Lógica da intervenção \\
\hline Santo André & $\begin{array}{l}\text { Áreas industriais ociosas ao } \\
\text { longo do Eixo Tamanduatehy }\end{array}$ & $\begin{array}{l}\text { Projeto Eixo Tamanduatehy (1998- } \\
2006) \text {. No lugar de vários galpões } \\
\text { ociosos se instalaram centros } \\
\text { comerciais, shopping, universidade, } \\
\text { faculdade, estacionamentos e } \\
\text { conjuntos habitacionais } \\
\text { O projeto não foi concluído. }\end{array}$ & $\begin{array}{l}\text { Mercado de consumo e imobiliário, com } \\
\text { contrapartida de obras sociais, } \\
\text { pontuais, fora do Eixo. } \\
\text { Ainda há áreas industriais ociosas à } \\
\text { espera de solução }\end{array}$ \\
\hline \multirow[t]{2}{*}{$\begin{array}{l}\text { São Bernardo } \\
\text { do Campo }\end{array}$} & $\begin{array}{l}\text { Antigo terreno das empresas } \\
\text { Brasmotor, Dodge Fargo, } \\
\text { Multibras, Brastemp }\end{array}$ & SBC Plaza Shopping (2012) & Mercado de consumo \\
\hline & $\begin{array}{l}\text { Antigo terreno da empresa } \\
\text { Tecelagem Tognato S/A }\end{array}$ & $\begin{array}{l}\text { Condomínio Residencial e Business } \\
\text { Domo (2007-2019) }\end{array}$ & $\begin{array}{l}\text { Especulação imobiliária, com obra de } \\
\text { integração social de lazer "Parque das } \\
\text { Bicicletas" (2019) }\end{array}$ \\
\hline $\begin{array}{l}\text { São Caetano } \\
\text { do Sul }\end{array}$ & $\begin{array}{l}\text { Antigo terreno da empresa } \\
\text { Cerâmica São Caetano }\end{array}$ & $\begin{array}{l}\text { Park Shopping São Caetano do Sul } \\
\text { (2011) }\end{array}$ & $\begin{array}{l}\text { Mercado de consumo e especulação } \\
\text { imobiliária }\end{array}$ \\
\hline \multirow[t]{2}{*}{ Mauá } & $\begin{array}{l}\text { Antigo terreno da empresa } \\
\text { Porcelana Schimidt }\end{array}$ & $\begin{array}{l}\text { Parte do terreno é ocupado pelo } \\
\text { Supermercado Roldão, uma parte se } \\
\text { transformou num estacionamento de } \\
\text { caminhões e a outra parte segue } \\
\text { ainda sem ocupação (2019) }\end{array}$ & Mercado de consumo \\
\hline & $\begin{array}{l}\text { Antigo terreno da empresa } \\
\text { Philips }\end{array}$ & Copafer (em obras) (2017) & Mercado de consumo \\
\hline \multirow[t]{2}{*}{ Ribeirão Pires } & $\begin{array}{l}\text { Antiga empresa Tecmafrig } \\
\text { Máquinas e Equipamentos } \\
\text { S/A }\end{array}$ & Supermercado Atacadista Açaí (2012) & Mercado de consumo \\
\hline & $\begin{array}{l}\text { Antiga empresa Ugimag do } \\
\text { Brasil }\end{array}$ & $\begin{array}{l}\text { Supermercado Atacadista Atacadão } \\
(2020)\end{array}$ & Mercado de consumo \\
\hline
\end{tabular}

Tab. 3. Síntese das principais intervenções urbanas por cidade na Região do Grande ABC após o Projeto Eixo Tamanduatehy. Fonte: Elaboração própria, a partir de informações de pesquisa de campo e informações de Moro Júnior (2007); Sakata (2009); Moussa (2005); Ferreira (2013); Oliveira (2015); BrMalls (2019); Multiplan (2019). 


\section{SÃOPAULO15 $17 \cdot$ LISBOA $25 \sim 26$ JUN 2020}

Ao mesmo tempo em que essas obras foram executadas, a Região passou por um novo período de crescimento econômico e recebeu investimentos diante do cenário positivo no mercado nacional e internacional entre os anos de 2003 e 2011 (Conceição \& Yamauchi, 2018). Entretanto, verificou-se, também, que as áreas industriais ociosas continuam fazendo parte da paisagem urbana das sete cidades. Algumas críticas sobre a lógica mercadológica e excludente foram apresentadas por Moro Júnior (2007), Teixeira (2010), entre outros autores, sobre o Projeto Eixo Tamanduatehy. A descontinuidade do projeto do Eixo aponta que há a necessidade da busca de novas soluções para essas áreas industriais ociosas.

Em face disso, Klink (2009, p. 30) defendeu, no final da década de 2000, novas formas de governança para a Região do Grande $A B C$, com base na experiência alemã dos projetos e acordos regionais que foram executados no Vale do Ruhr, região que também passou pelo processo de saída e fechamento de indústrias, levando à formação de áreas industriais ociosas. No caso internacional, os projetos foram realizados sob a governança multinível, com a Câmara Regional e outros atores de diversas instâncias, formando um pacto social e político em prol da revitalização da região.

Ainda que alguns estudiosos tenham chamado atenção sobre o problema nos últimos anos, observa-se que a discussão na Região, por amplos setores da sociedade, inclusive do poder público, perdeu fôlego a partir dos anos 2000. Paradoxalmente, em termos quantitativos, pode-se observar, pelas Tabs. 4 e 5 , que a problemática das áreas industriais ociosas na Região do Grande $A B C$ aumentou.

\begin{tabular}{|c|c|c|c|c|c|c|c|c|}
\hline \multirow{2}{*}{$\begin{array}{l}\text { Tamanho do estabelecimento por } \\
\text { no de empregados }\end{array}$} & \multicolumn{8}{|c|}{$\begin{array}{l}\text { Total de estabelecimentos industriais no Grande ABC, por tamanho, no período entre } \\
2002-2017\end{array}$} \\
\hline & 2002 & 2005 & 2008 & 2011 & 2014 & 2015 & 2016 & 2017 \\
\hline 0 empregado & 267 & 266 & 316 & 339 & 361 & 415 & 416 & 388 \\
\hline de 1 a 4 empregados & 1535 & 1626 & 1776 & 1943 & 2126 & 2140 & 2193 & 2148 \\
\hline de 5 a 9 empregados & 914 & 983 & 1102 & 1155 & 1140 & 1163 & 1091 & 1089 \\
\hline de 10 a 19 empregados & 919 & 1013 & 1136 & 1121 & 1124 & 1102 & 1084 & 1053 \\
\hline de 20 a 49 empregados & 717 & 776 & 916 & 999 & 908 & 858 & 773 & 745 \\
\hline de 50 a 99 empregados & 306 & 368 & 424 & 415 & 366 & 341 & 303 & 287 \\
\hline de 100 a 249 empregados & 180 & 205 & 243 & 247 & 235 & 214 & 183 & 194 \\
\hline de 250 a 499 empregados & 74 & 97 & 99 & 94 & 86 & 71 & 71 & 61 \\
\hline de 500 a 999 empregados & 33 & 38 & 45 & 43 & 35 & 34 & 31 & 31 \\
\hline 1000 ou mais empregados & 17 & 21 & 28 & 28 & 25 & 21 & 19 & 17 \\
\hline Total & 4962 & 5393 & 6085 & 6384 & 6406 & 6359 & 6164 & 6013 \\
\hline
\end{tabular}

Tab. 4. Total de Estabelecimentos Industriais no Grande ABC, por tamanho, no período entre 2002-2017. Fonte: Elaboração própria, a partir das informações do CAGED, Ministério da Economia, 2019.

Na Fig. 2, quando comparada com a Fig. 1, é possível observar na Região do Grande ABC Paulista os efeitos da reestruturação produtiva, principalmente na fragmentação dos estabelecimentos industriais, no 


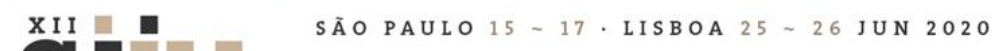

Seminário Internacional de Seminario Internacional de Investigação em Urbanismo Investigación en Urbanismo

sentido da desconcentração espacial, bem como do aumento de estabelecimentos com menos empregados (Tab. 4 e 5). ${ }^{1}$

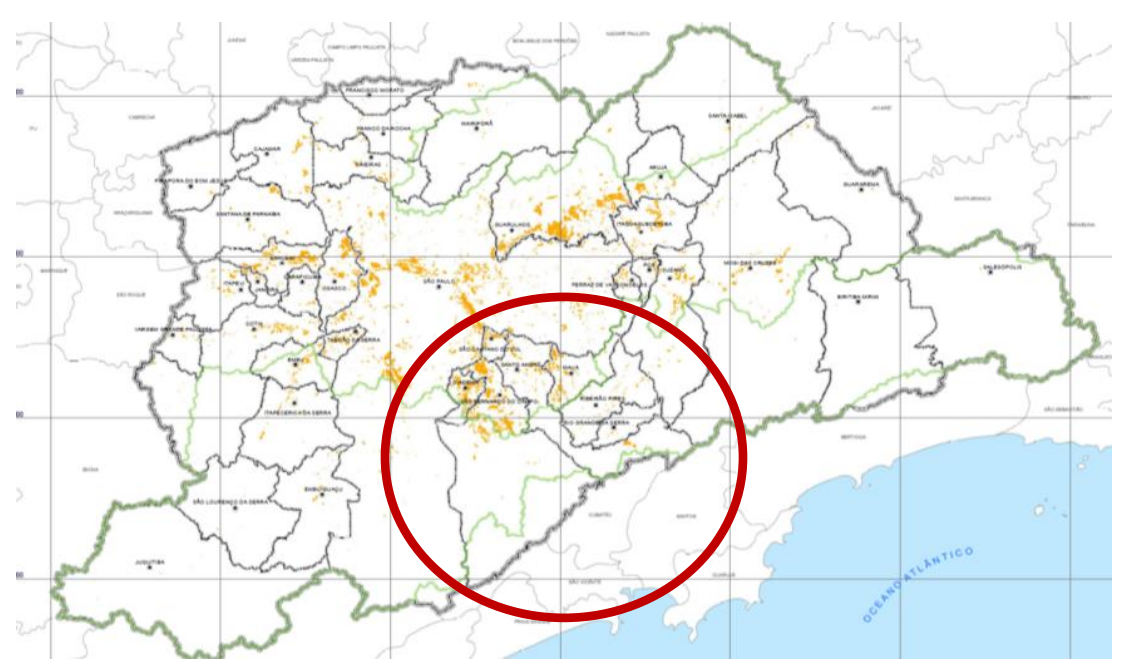

Fig. 2. Uso e ocupação do solo da Região Metropolitana de São Paulo, com destaque para o Grande ABC em 2006.

Fonte: (Emplasa, 2006: p. 17).

Na Tab. 4 é possível observar os efeitos positivos dos novos investimentos na Região entre o período de 2002 a 2011 e os efeitos negativos a partir do ano de 2012. Junto a esses últimos, nota-se, na Tab. 5, que os períodos compreendidos entre os anos de 1996 a 1999 e entre 2014 a 2018 foram intensos em relação ao fechamento de indústrias no Grande ABC, elevando o número de galpões industriais ociosos na Região.

\begin{tabular}{|c|c|c|c|c|c|c|c|c|c|c|c|c|c|c|}
\hline $\begin{array}{l}\text { Tamanho } \\
\text { por no } \quad \text { de } \\
\text { empregados }\end{array}$ & $\begin{array}{l}\text { Saldo } \\
1989- \\
1988\end{array}$ & $\begin{array}{l}\text { Saldo } \\
1990- \\
1989\end{array}$ & $\begin{array}{l}\text { Saldo } \\
1994- \\
1990\end{array}$ & $\begin{array}{l}\text { Saldo } \\
1996- \\
1994\end{array}$ & $\begin{array}{l}\text { Saldo } \\
1999- \\
1996\end{array}$ & $\begin{array}{l}\text { Saldo } \\
2002- \\
1999\end{array}$ & $\begin{array}{l}\text { Saldo } \\
2005- \\
2002\end{array}$ & $\begin{array}{l}\text { Saldo } \\
2008- \\
2005\end{array}$ & $\begin{array}{l}\text { Saldo } \\
2011- \\
2008\end{array}$ & $\begin{array}{l}\text { Saldo } \\
2014- \\
2011\end{array}$ & $\begin{array}{l}\text { Saldo } \\
2015- \\
2014\end{array}$ & $\begin{array}{l}\text { Saldo } \\
2016- \\
2015\end{array}$ & $\begin{array}{l}\text { Saldo } \\
2017- \\
2016\end{array}$ & $\begin{array}{l}\text { Saldo } \\
2018- \\
2017\end{array}$ \\
\hline 0 empregado & - & - & - & - & - & - & -1 & 50 & 23 & 22 & 54 & 1 & -28 & 40 \\
\hline de 1 a 4 empreg. & 401 & 249 & 132 & 141 & -65 & -273 & 91 & 150 & 167 & 183 & 14 & 53 & -45 & -14 \\
\hline de 5 a 9 empreg. & 26 & 33 & 38 & 68 & 2 & 112 & 69 & 119 & 53 & -15 & 23 & -72 & -2 & 13 \\
\hline de 10 a 19 empreg. & -19 & 3 & 81 & 38 & 80 & 133 & 94 & 123 & -15 & 3 & -22 & -18 & -31 & -36 \\
\hline de 20 a 49 empreg. & 29 & 19 & -33 & 17 & 2 & 120 & 59 & 140 & 83 & -91 & -50 & -85 & -28 & 1 \\
\hline de 50 a 99 empreg. & -8 & -44 & -55 & 2 & -26 & 44 & 62 & 56 & -9 & -49 & -25 & -38 & -16 & 9 \\
\hline $\begin{array}{l}\text { de } 100 \text { a } 249 \\
\text { empreg. }\end{array}$ & 15 & -50 & 9 & -52 & -59 & 3 & 25 & 38 & 4 & -12 & -21 & -31 & 11 & -25 \\
\hline de 250 a 499 & 5 & -21 & -24 & -10 & -13 & -2 & 23 & 2 & -5 & -8 & -15 & 0 & -10 & 1 \\
\hline
\end{tabular}

\footnotetext{
${ }^{1}$ Infelizmente, não encontramos levantamentos de uso do solo da Região do Grande ABC, após o ano 2012, quando os efeitos negativos da crise econômica, acima referida, se intensificam. Mesmo mapas elaborados mais recentemente utilizam dados até 2010.
} 


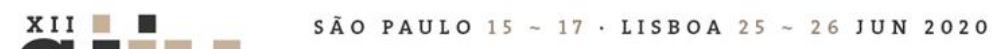

empreg.

\begin{tabular}{|c|c|c|c|c|c|c|c|c|c|c|c|c|c|c|c|c|}
\hline empreg. & & & 4 & -11 & -7 & -10 & -12 & 3 & 5 & 7 & -2 & -8 & -1 & -3 & 0 & 3 \\
\hline $\begin{array}{l}1000 \\
\text { empreg. }\end{array}$ & ou & mais & 1 & -12 & -4 & -9 & -11 & 3 & 4 & 7 & 0 & -3 & -4 & -2 & -2 & 0 \\
\hline Total & & & 218 & 166 & 137 & 185 & -102 & 410 & 431 & 692 & 299 & 22 & -47 & -195 & -151 & -8 \\
\hline
\end{tabular}

Tab. 5. Saldo dos estabelecimentos industriais na Região do Grande ABC, por número de empregados, 1988-2018. Fonte: Elaboração própria, a partir de dados da RAIS/CAGED do Ministério da Economia (antigo Ministério do Trabalho e Emprego) entre os anos de 1988 e 2018.

Esses dados e a falta de informação nas prefeituras dos municípios do Grande ABC ensejaram a necessidade da realização de pesquisa que identificasse e dimensionasse as áreas industriais hoje ociosas na Região. Dessa forma, realizou-se pesquisa em imobiliárias online e de levantamento de campo dos imóveis antes industriais, incluindo as áreas subutilizadas, disponíveis para locação ou venda em 2019, em cada município, mostrando o resultado total da Tab. 6.

\begin{tabular}{lcc}
\hline Galpão, Depósitos e Armazéns & entre 5000 e $9999 \mathrm{~m}^{2}$ & a partir de $10000 \mathrm{~m}^{2}$ \\
\hline TOTAL DO GRANDE ABC & 197 & 111 \\
\hline
\end{tabular}

Tab. 6. Quantidade de galpões, depósitos e armazéns ociosos, por porte, no Grande ABC em 2019. Fonte: Elaboração própria, a partir de dados do Zap Imóveis, VivaReal Imóveis, Ballarin Imóveis, Costa Nascimento Imóveis, RD Imóveis Imóveis, Paulo Bio Imóveis, Invictus Imóveis, Sanca Imóveis, entre outras imobiliárias online e pesquisa de campo (2019).

A referida pesquisa revelou que houve uma reconfiguração do porte dessas áreas industriais ociosas na Região do Grande ABC. Isto é, além de grandes áreas industriais ociosas (a partir de $10.000 \mathrm{~m}^{2}$ ) ainda presentes nos municípios, ocorreu uma fragmentação dessas no território, pois houve a ampliação do número de áreas industriais ociosas, e o fato de que, agora, são, em sua maioria, de pequeno e médio porte (entre $5.000 \mathrm{~m}^{2}$ e $9.999 \mathrm{~m}^{2}$ ). Além disso, foi encontrado um número expressivo de grandes galpões a partir de $10.000 \mathrm{~m}^{2}$ e ainda existem áreas que permanecem à espera de uma solução desde a década de 1990, totalizando, atualmente, cerca de 300 áreas ociosas nos sete municípios do Grande ABC.

Contudo, mesmo diante desse panorama, o debate na Região tem sido escasso. Entre os anos de 2017 e 2018, Tourinho e Yamauchi (2019) indicam a ocorrência de dois eventos pontuais sobre o desenvolvimento da Região do Grande ABC. O primeiro deles, o "Multilevel Governance em prol do desenvolvimento regional sustentável nas aglomerações urbanas do Ruhr e do ABC Paulista", realizado pelo Centro Alemão de Ciência e Inovação, Universidade Federal do ABC e Aliança das Universidades do Ruhr que debateram diversos temas. O segundo, o Seminário "Arquitetura e Cidade: desenvolvimento sustentável e qualidade do espaço público no Grande ABC", realizado pela Universidade Municipal de São Caetano do Sul, focou várias temáticas sobre o planejamento territorial regional. Em ambos eventos, houve apenas uma pequena menção sobre o problema.

$\mathrm{Na}$ esfera regional, observa-se um enfraquecimento nas discussões regionais: Diadema saiu do Consórcio Intermunicipal do $A B C$ e os municípios de São Caetano do Sul e Rio Grande da Serra votaram também a favor da saída; houve uma diminuição do protagonismo da Agência de Desenvolvimento Econômico do ABC. 


\section{SÃO PAULO15 17 LISBOA $25 \sim 26$ JUN 2020

Nas esferas municipais, constata-se, pela análise dos planos diretores das sete cidades da Região (Lei $\mathrm{n}^{\circ}$ 9.394/12 de Santo André, Lei no 6384/11 e 6374/14 de São Bernardo do Campo, Lei no 5.374/15 de São Caetano do Sul, Lei complementar no 273 e no 83/07 de Diadema, Lei no 4153/07 de Mauá, Lei no 5907/14 e no 5779/13 de Ribeirão Pires e a Proposta de Rio Grande da Serra), que nenhum deles contempla ações específicas e estratégicas diante da gravidade do problema.

Esse "esquecimento" da problemática, nos últimos anos, suscita a pergunta sobre o conhecimento, pelos atores sociais da Região, da situação presente da questão. Para aferir o conhecimento do problema pelos atores sociais, foi realizada pesquisa que entrevistou técnicos e gestores das administrações públicas municipais das sete cidades, representantes do Consórcio Intermunicipal e do setor empresarial - do Centro das Indústrias do Estado de São Paulo, de Santo André (CIESP) -, bem como um representante sindical, do Instituto Trabalho Indústria e Desenvolvimento (TiD-Brasil). As entrevistas revelaram que há um desconhecimento da realidade sobre as áreas industriais ociosas pelos atores da Região, não havendo nenhum levantamento preciso sobre elas.

\section{Considerações Finais}

Sob a égide das ideias neoliberais, as respostas dadas pelas políticas públicas na Região do Grande ABC Paulista permanecem as mesmas, centradas no mercado de consumo e nas demandas do mercado imobiliário. Esse cenário desfavorável é acentuado pelo desconhecimento da dimensão do problema pelos atores sociais da Região, o que não possibilita a percepção de que esses galpões industriais ociosos demandam maior análise, planejamento, respostas e ações mais complexas.

Ressalta-se, ainda, que há uma tendência de piora da situação das áreas industriais ociosas, considerandose os seguintes aspectos: 1) o país atravessa um período de crise econômica, que demandará tempo para recuperação; 2) a pauta da indústria está fora do planejamento estratégico da atual gestão do governo federal, cujos efeitos acabam rebatendo no planejamento estratégico da Região do Grande ABC; 3) há um grande descolamento tecnológico da Região do Grande ABC no âmbito das cadeias globais de valor dos países desenvolvidos; 4) os principais setores industriais presentes na Região são o automotivo e o químico, os quais passam por grandes transformações de ordem mundial no momento, que podem se traduzir em novas mudanças nas empresas presentes na Região; 5) houve uma mudança no perfil dos empregos da Região do setor da indústria para o setor de serviços, traduzindo-se numa diminuição de renda dos trabalhadores; 6) o percentual do valor agregado industrial da Região do Grande ABC vem perdendo espaço na participação do Estado de São Paulo; 7) há uma perda do diálogo e interação entre os diferentes atores sociais da Região do Grande $A B C$; 8 ) a lógica neoliberal aplicada à gestão pública não permite que os projetos de cunho social sejam contemplados. Como consequência, verifica-se a manutenção da lógica de solução centrada nos interesses absolutistas do mercado de consumo e imobiliário, que não permite ir em busca de novas soluções.

Nesse quadro, se as ações não fugirem das lógicas eleitoral, consumista e imobiliária, a situação caminha para a piora no quadro da crise regional. É preciso que novos projetos contemplem as necessidades da sociedade civil. Essas novas soluções podem buscar vários exemplos no Brasil e no mundo, por meio do intercâmbio entre cidades e regiões, no aprendizado com os erros cometidos nos projetos que não deram certo. O sucesso desse desafio depende do resgate da interação e cooperação entre os atores sociais em discutir soluções para essas áreas industriais ociosas, superando os conflitos, para que, assim, decidam-se os novos rumos para a Região do Grande ABC, recolocando-a nos trilhos do desenvolvimento e crescimento. 


\section{SÃOPAULO15 $17 \cdot$ LISBOA $25 \sim 26$ JUN 2020}

\section{REFERÊNCIAS}

\subsection{Bibliografia}

ARCHER, François (2010). Os novos princípios do urbanismo. São Paulo: Romano Guerra.

HOBSBAWN, Eric J (2015). A era dos extremos - o breve século XX 1914-1991. São Paulo: Companhia das Letras.

KLINK, Jeroen J (2001). A cidade-região: Regionalismo e reestruturação no grande ABC Paulista. Rio de Janeiro: DP\&A Editora.

MORO JUNIOR, Enio (2007). A redenção inexistente nos planos urbanísticos municipais: o caso do Projeto Eixo Tamanduatehy. Annablume.

\subsection{Fontes Eletrônicas}

BRMALLS (2019). Sobre 0 São Bernardo Plaza Shopping. https://www.shoppingsaobernardoplaza.com.br/sobre (Acesso: 30/10/2019).

CONCEIÇÃO, Jefferson José da (2006). Quando o apito da fábrica silencia: atores sociais diante da reestruturação do parque industrial da Região do ABC. Tese (Doutoramento em Sociologia). Universidade de São Paulo, USP, São Paulo. http://blogjeffdac.blogspot.com.br/search/label/TESE\%20DE\%20DOUTORAMENTO (Acesso: 01/11/2019).

CONCEIÇÃO, Jefferson J. e YAMAUCHI, Gisele (2018). O valor adicionado da indústria do Grande ABC Paulista e a atual retração cíclica da economia. In: Universidade Municipal de São Caetano do Sul. Carta de Conjuntura, ed. 2, mai., 2018. http://noticias.uscs.edu.br/uscs-lanca-2a-carta-de-conjuntura/ (Acesso: 20/11/2019).

EMPRESA PAULISTA DE PLANEJAMENTO METROPOLITANO S/A (EMPLASA). Atlas de Uso e Ocupação do Solo do Município de Mauá. São Paulo: EMPLASA, 2006. Disponível em: <http:// https://emplasa.sp.gov.br/Cms_Data/Sites/EmplasaDev/Files/Documentos/Cartografia/Atlas/RMSP/Atlas_Ma ua.pdf> (Acesso em: 20.jul.2020).

FERREIRA, Josué Catharino (2013). As alterações na estrutura industrial de Santo André (1975-2013). Dissertação (Mestrado em Ciências Humanas e Sociais). Universidade Federal do ABC, UFABC, Santo André. http://www.academia.edu/download/37905834/DISSERTACAO.pdf (Acesso: 16/11/2019).

KLINK. Jeroen J (2009). Novas governanças para as áreas metropolitanas. O panorama internacional e as perspectivas para o caso brasileiro. Cadernos Metrópole, v. 11, n. 22, 2009. http://www.redalyc.org/html/4028/402837806006/ (Acesso: 10/11/2019).

MARICATO, Ermínia. Urbanismo na periferia do mundo globalizado: metrópoles brasileiras. São Paulo em Perspectiva, São Paulo, v. 14, n. 4, p. 21-33, out. 2000. http://www.scielo.br/scielo.php?script=sci_arttext\&pid=S0102-88392000000400004\&lng=en\&nrm=iso (Acesso: 28/10/2019).

MOUSSA, Amer N (2005). O Rio Tamanduateí e o desenho urbano. Monografia (Disciplina de AUP 272). São Paulo, 


\section{SÃO PAULO15 17 LISBOA $25 \sim 26$ JUN 2020}

Seminário Internacional de Investigação em Urbanismo

http://www.fau.usp.br/cursos/graduacao/arq_urbanismo/disciplinas/aup0272/6t-alun/2005/m4moussa/index.html (Acesso: 07/11/2019).

MULTIPLAN (2019). O Shopping - o projeto arquitetônico. https://www.parkshoppingsaocaetano.com.br/oshopping (Acesso: 29/10/2019).

OLIVEIRA, Henry dos Santos (2015). A (des)construção de uma nova centralidade: Cidade Tognato em Săo Bernardo do Campo. (Dissertação de Mestrado) Universidade Presbiteriana Mackenzie, São Paulo. http://tede.mackenzie.br/jspui/handle/tede/382 (Acesso: 07/11/2019).

SAKATA, Margarida Nobue (2009). Novos instrumentos de gestão urbana e regional: Santo André e o caso do projeto eixo Tamanduateí. Pós. Revista do Programa de Pós-Graduação em Arquitetura e Urbanismo da FAUUSP, n. 25, p. 186-199. http://www.periodicos.usp.br/posfau/article/view/43615/47237 (Acesso: 12/11/2019).

TEIXEIRA, Aparecida Netto (2010). A produção do espaço público no projeto urbano Eixo Tamanduatehy (Santo André, SP). Arquitextos (São Paulo), 122.04, n. 11, jul. 2010. http://www.vitruvius.com.br/revistas/read/arquitextos/11.122/3483 (Acesso: 31/11/2019).

TOURINHO, Andréa de Oliveira e YAMAUCHI, Gisele (2019). Áreas industriais degradadas na Região do Grande ABC Paulista - Velhos problemas, novas ideias. Anais XVIII ENANPUR 2019. Natal, UFRN. http://anpur.org.br/xviiienanpur/anaisadmin/capapdf.php?reqid=833 (Acesso: 31/11/2019). 